\title{
Determination of the Candidiasis Marker in the Urine of Autistic Children
}

\author{
Joanna Kałużna-Czaplińska, Wioletta Grys, Anna Rozetti-Szymańska
} and Jacek Rynkowski

Institute of General and Ecological Chemistry, Lodz University of Technology, Poland joanna.kaluzna-czaplinska@p.lodz.pl

Institute of General and Ecological Chemistry, Lodz University of Technology, Poland

wioletta.grys@interia.pl

Navicula Centre, Lodz, Poland

centrum@navicula.pl

Institute of General and Ecological Chemistry, Lodz University of Technology, Poland

\section{ABSTRACT}

jacek.rynkowski@p.lodz.pl

Introduction: Determination of the $\mathrm{D} / \mathrm{L}$-arabinitol ratio in urine appears to be a useful diagnostic test to indicate overgrowth of Candida yeast. The aim of this study was to find out whether levels of D/L-arabinitol ratio in the urine of children with autism are heightened.

Material and methods: D/L-arabinitol ratio in urine was determined by capillary gas chromatography with electron capture detection (GC-ECD). Urine samples were collected from 83 autistic children (2.5-16 years old) and from 50 healthy children (1.5-16 years old).

Results: (16.87\%) of autistic children under study had an elevated D/L ratio in urine (>4.25). For 8 of them, the stated norm was exceeded less than twice (D/L: 4.39-6.98); for 4 of them the levels of $\mathrm{D} / \mathrm{L}$-arabinitol were higher than cutoff limit 2-3 times (D/L: 8.57-11.6); for 1 child the norm was exceeded over 5 -times (D/L: 21.76 ); 1 child had a highly rebounding value (D/L: 89.13$)$.

Conclusion: Some of the autistic children show a raised D/L- arabinitol ratio in urine. Such percentage, in comparison to that reported in literature for other hospitalized patients, is lower than in the case of hematological, cardiac diseases and cancer, but higher than in the case of children from intensive care unit and persons after long term antibiotic therapies.

\section{Indexing terms/Keywords}

D/L- arabinitol ratio, Candida infection, autism

\section{Academic Discipline And Sub-Disciplines}

analytical chemistry

\section{SUBJECT CLASSIFICATION}

clinical chemistry

\section{TYPE (METHOD/APPROACH)}

experimental study

\section{Council for Innovative Research}

Peer Review Research Publishing System

Journal: Journal of Advances in Chemistry

Vol 4, No. 1

editor@cirworld.com

www.cirworld.com, member.cirworld.com 


\section{Introduction}

Autism is a pervasive developmental disorder characterized by impaired social interaction and communication and repetitive behaviour, which influences brain cells as well as the digestive and immune systems [1, 2]. There is still very little known about its causes. Most probably there are several of them - genetic, metabolic and environmental (exposure to toxic substances, oxidative stress, nutritional deficiencies, improper diet, excessive intake of antibiotics) [3-6].

One of the hypotheses presumes that autism can result from metabolism disorders [3, 7]. According to this theory, it can be caused by exogenous peptides and their influence on neurotransmission in the central nervous system. Those peptides probably originate from incomplete decomposition of some foods and the proteins they contain, especially gluten and casein. Casein is digested in the stomach to form peptides called casomorphines, which possess opioid-like activity. Similar peptides resulting from gluten digestion are called glutenomorphins [7-8]. Urine analyses show that in 70$80 \%$ of autistic patients the levels of substances with opioid-like properties are increased. It has also been proved that deficiency of some vitamins (C, B6, B12, A, E and folic acid) and microelements (zinc, magnesium, selenium, chromium) in autistic children can additionally increase the symptoms of autism [9-11].

There is an opinion that a form of yeast, Candida species (mainly C. albicans), may exacerbate behavior and health problems in autistic individuals, especially those with late-onset autism [12]. Candida is a unicellular fungus belonging to the yeast family (class Saccharomycetes). It is found in various areas of the body, including the digestive system. In certain favorable conditions, e.g. metabolic acidosis or intestinal putrefaction, which happen during a bacterial or viral infection accompanied by fever, it becomes a pathogen. Immune deficiency accelerates its development. It forms a mycelium which grows into surrounding tissues and causes damage to them. The fungus also secretes specific toxins, which additionally weakens the immune system and act directly on the central nervous system [13]. A large number of studies have indicated a wide number of abnormalities of the immune system in autism. Immune deficiencies lead to an increased frequency of infections that are almost always treated with antibiotics. As a result, a proliferation of Candida yeast and bacteria occur in the gastrointestinal tract. Shaw et al. found the presence of microbial metabolites in the urine of autistic patients. Antifungal treatment can result in the improvement of eye contact, speech and concentration in autistic persons [14]. D-arabinitol is the main metabolite characteristic of several Candida species. The urine D- to L-arabinito concentration ratio reflects the same ratio in blood $[15,16]$. There is evidence that elevated levels of $D$-arabinitol in urine or serum is a positive indication of Candida overgrowth, even if invasive candidiasis is not present [17].

The aim of this study was to find out whether there are heightened levels of $\mathrm{D} / \mathrm{L}$-arabinitol ratio in the urine of children with autism. A simple method for the monitoring of the D/L-arabinitol ratio in urine by gas chromatography with electron capture detection (GC-ECD) was applied.

\section{Material and methods}

\subsection{Participants}

Overnight urine samples were collected from 83 autistic children (2.5-16 years old, 7.16 \pm 3.18$)$ who underwent rehabilitation in the Navicula-Centre in Lodz. All autistic children were assessed and diagnosed by clinicians specializing in the diagnosis and management of autistic children from the Navicula. The control group consisted of 50 potentially

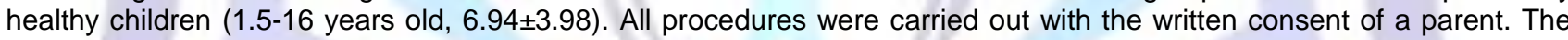
study was performed in agreement with the Standards and Ethics in Biological Rhythm Research [18]. An approval was given by Committee of Scientific Research Ethics of Polish Mother's Memorial Hospital - Research Institute in Lodz, Poland.

\subsection{Analytical method}

In order to determine the urinary $\mathrm{D} / \mathrm{L}$ ratio a method of gas chromatography with electron capture detection (GC-ECD) was applied. A gas chromatograph-electron capture detector (Agilent Technology) with an autosampler was used. A fused silica column coated with $\beta$-cyclodextrin layer ( $\beta$-dex 120 Supelco, $30 \mathrm{~m}$ length, $0.25 \mathrm{~mm}$ diameter and $0.25 \square \mathrm{m}$ film thickness) was applied in order to separate enantiomers. The method measured the $\mathrm{D} / \mathrm{L}$ ratio from peak areas. The use of an internal standard and calculation of the absolute concentration of enantiomers was not required [19]. Typical GC-ECD chromatogram of urine is shown in Figure 1. 


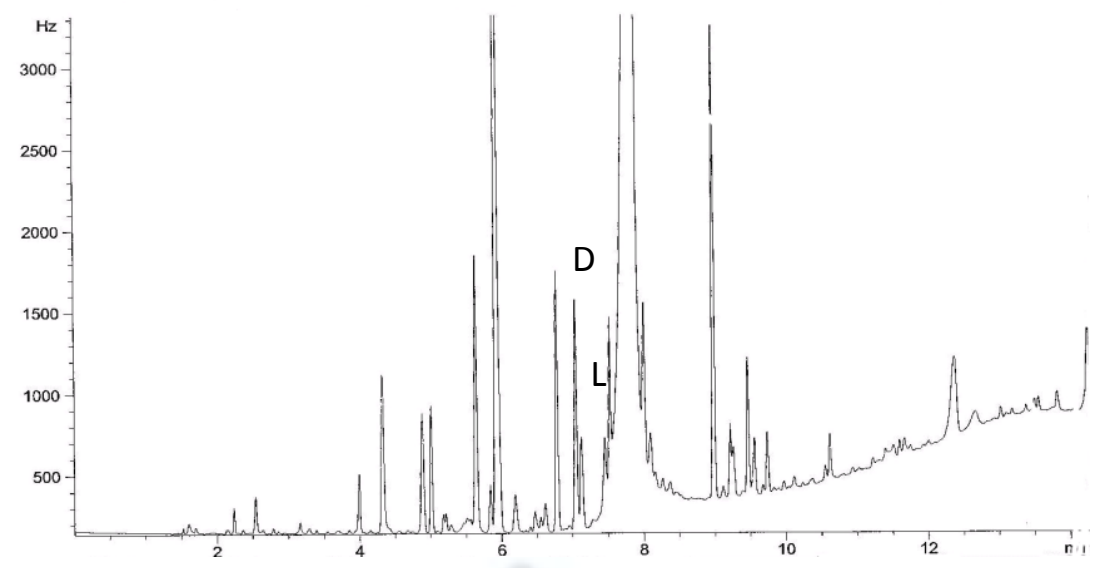

Figure 1. Chromatogram of D/L-arabinitol in urine

\subsection{Statistical analysis}

Data were statistically evaluated using statistical analysis package (StatSoft, Polska STATISTICA, version 9.0.). The Shapiro-Wilk test was used to check for normal distribution of the results. The Mann-Whitney test was applied to check differences in variables in groups. The level of statistical significance was defined as $p<0.05$.

\section{Results}

The analyses of $\mathrm{D} / \mathrm{L}$-arabinitol ratio were carried out in the urine samples collected from 83 autistic children (80 males and 3 females) and 50 healthy children ( 34 males and 16 females). The applied method was described in detail in our earlier paper [19]. The distribution of the variable $\mathrm{D} / \mathrm{L}$ ratio for the whole group of autistic children and controls was not normal at an accepted alpha level (Shapiro-Wilk test probabilities p: 0.00 and 0.03 , respectively). The basic statistical parameters for the D/L-arabinitol ratio in the urine of children under investigation were shown in Table 1.

The calculated probability of Mann-Whitney test $(p=0.11)$ indicates that there are not significant differences between the average results of the urinary $\mathrm{D} / \mathrm{L}$ ratio expressed as medians between the two groups. The maximum value for the control group (4.25) was stated as the upper cutoff limit. 14 children (16.87\%) had an elevated D/L ratio (male/female: 11/3). For 8 of them, the stated norm was exceeded less than twice (D/L: 4.39-6.98); for 4 of them the levels of $\mathrm{D} / \mathrm{L}$-arabinitol were higher than cutoff limit 2-3 times (D/L: 8.57-11.6); for 1 child the norm was exceeded over 5times (D/L: 21.76); 1 child had a highly rebounding value (D/L: 89.13).

Table 1. The basic statistical parameters for the $D / L$-arabinitol ratio in urine of children under investigation.

\begin{tabular}{lll} 
& & \\
\hline D/L-arabinitol ratio & autistic children $(\mathbf{n = 8 3})$ & control individuals $(\mathbf{n}=\mathbf{5 0})$ \\
\hline median & 1.86 & 2.06 \\
interquartile range & $1.34-2.52$ & $1.61-2.54$ \\
range & $0.42-89.13$ & $1.12-4.25$ \\
\hline
\end{tabular}

\section{Discussion}

The overgrowth of Candida can be caused by a long-term antibiotic therapy, stress, steroids and oral contraceptives. The overgrowth of Candida in the gut can lead to a myriad of symptoms, which include but are not limited to: chronic fatigue, especially after an increase in body temperature, depression, gastrointestinal problems such as: bloating, gas, intestinal cramps, chronic diarrhea, constipation, or heartburn, allergies (including both food and airborne) [20-22]. When yeasts multiply in the body, toxins which disrupt the work of the central nervous system and immune system are released [21]. Clinical signs of invasive candidiasis can be unspecific, and the diagnosis is mostly based on blood cultures. However, blood cultures have been assumed to be positive for Candida in only 24 to $60 \%$ of cases [23]. Human mammalian cells are capable of producing both $\mathrm{D}$ - and L-arabinitol. D-arabinitol, in contrast to L-arabinitol, is produced by fungi of the genus Candida. An elevated D/L-arabinitol ratio is a sensitive sign of invasive candidiasis. The $\mathrm{D} / \mathrm{L}$-arabinitol ratio is most frequently analyzed by enzymatic assays [24], electrochemical method [25], liquid 
chromatography (LC) or LC/mass spectrometry (LC/MS)[26, 27] and gas chromatography (GC) or GC/mass spectrometry $[15,28]$. The enzymatic assays are involved in the maintenance of enzyme activity and false positive results by competition reaction [29]. The chromatographic methods are very desirable and helpful in the diagnosis of disseminated candidiasis. We determined the $\mathrm{D} / \mathrm{L}$ ratio by gas chromatography with electron capture detection in the urine samples from the autistic and healthy children. $(16.87 \%)$.

In our current research only a proportion of the autistic children under investigation had raised $D / L$ ratio in urine

The $\mathrm{D} / \mathrm{L}$ - arabinitol ratio is often elevated in patients suffering from serious immunological system diseases. Lehtonen and co-authors discovered an elevated $\mathrm{D} / \mathrm{L}$ ratio in urine among $31.15 \%$ of adults suffering from hematological malignancies (also patients with acute leukemia) [30]. D/L-arabinitol is a useful diagnostic marker for candidiasis among neutropenic patients and among other high-risk groups. Some papers describe studies of $\mathrm{D} / \mathrm{L}$ - arabinitol ratio in children's urine. Stradomska and co-authors showed an elevated D/L ratio in urine among $20.29 \%$ children with cardiac diseases [31]. Elevated D/L ratios in urine were reported among $26 \%$ children with cancer [32]. $11.97 \%$ infants from an intensive care unit had an elevated $\mathrm{D} / \mathrm{L}$ ratio in their urine [33]. However, only $7.84 \%$ children after long-term antibiotic therapies had a higher urinary $\mathrm{D} / \mathrm{L}$ ratio [34].

\section{Conclusions}

In our current research a proportion of the autistic children under investigation had raised $\mathrm{D} / \mathrm{L}$ ratio in urine $(16.87 \%)$. Such percentage, in comparison to that reported in literature for other hospitalized patients, is lower than in the case of hematological, cardiac diseases and cancer, but higher than in the case of children from intensive care unit and patients after long term antibiotic therapies [30-34].

\section{ACKNOWLEDGMENTS}

The authors like to thank the parents of autistic children treated in the Navicula Centre (Lodz, Poland), the staff of Polish Mother's Memorial Hospital - Research Institute (Lodz, Poland) and Lodz University of Technology (Lodz, Poland) for their collaboration especially in collecting the samples for analysis.

\section{REFERENCES}

[1] Manning-Courtney, P., Brown, J., Molloy, C.A., Reinhold, J., Murray, D. 2003. Diagnosis and treatment of autism spectrum disorders. Cur. Prob. Ped. Adol. Health 33, 283-304.

[2] Newschaffer, C.J., Curran, L.K. 2003. Autism: an emerging public health problem. Public Health Rep. 118, 393-399.

[3] Adams, J.B., Holloway, C. 2004. Pilot study of a moderate dose multivitamin/mineral supplement for children with autistic spectrum disorder. J. Altern. Complement. Med. 10,1033-1039.

[4] Kałużna-Czaplińska, J., Socha, E., Rynkowski, J. 2010. Determination of homovanillic acid and vanillylmandelic acid in urine of autistic children by gas chromatography/ mass spectrometry. Med. Sci. Monit. 16, 445-450.

[5] James, S.J., Cutler, P., Melnyk, S., Jernigan, S., Janak, L., Gaylor, D.W., Neubrander, J.A. 2004. Metabolic biomarkers of increased oxidative stress and impaired methylation capacity in children with autism. Am. J. Clin. Nutr. 80,1611-1617.

[6] Poling, J.S., Frye, R.E. 2006. Developmental regression and mitochondrial dysfunction in a child with autism. J. Child. Neurol. 21, 170-172.

[7] Shattock, P., Whiteley, P. 2002. Biochemical aspects in autism spectrum disorders: updating the opioid-excess theory and presenting new opportunities for biomedical intervention. Expert. Opin. Ther. Targets. 6, 1-9.

[8] Page, T. 2000. Metabolic approaches to the treatment of autistic spectrum disorder. J. Autism. Dev. Disord. 30, 461467.

[9] Peters, V. , Garbade, S.F., Langhans, C.D., Hoffmann, G.F., Pollitt, R.J., Downing, M., Bonham, J.R. 2008. Qualitative urinary organic acid analysis: Methodological approaches and performance. J. Inherit. Metab. Dis. 31, 690-696.

[10] Kałużna-Czaplińska, J., Michalska, M., Rynkowski, J. 2011. Vitamin supplementation reduces the level of homocysteine in the urine of autistic children. Nutr. Res. 31, 318-321.

[11] Kałużna-Czaplińska, J., Socha, E., Rynkowski, J. 2011. B vitamin supplementation reduces excretion of urinary dicarboxylic acids in autistic children. Nutr. Res. 31, 497-502.

[12] Shaw, W., Kassen, E., Chaves, E. 1995. Increased excretion of analogs of Krebs cycle metabolites and arabinose in two brothers with autistic features. Clin. Chem. 41, 1094-1104.

[13] Clack, S. Candidiasis and dysbiosis in children with autistic spectrum disorders. IHP, December 2008/January 2009, 80-83, http://www.touchstonecentre.com/pdf/lssue\%206\%20candidiasis\%20ASD.pdf 
[14] Shaw, W., Kassen, E., Chaves, E. 2000. Assessment of antifungal drug therapy in autism by measurement of suspected microbial metabolites in urine with gas chromatography-mass spectrometry. Clin. Prac. Alter. Med. 1, 1526.

[15] Hui, M., Cheung, S.W., Chin, M.L., Chu, K.Ch., Chiu-Yeung Chan, R., Fun-Bun Cheng, A. 2004. Development and application of a rapid method for invasive candidiasis by the detection of $\mathrm{D}$-/L-arabinitol using gas chromatography/mass spectrometry. Diagn. Microbiol. Infect. Dis. 49,117-123.

[16] Sigmundsdottir, G., Christensson, B., Björklund, L.J., Hakansson, K., Pehrson, Ch., Larsson, L. 2000. Urine Darabinitol/L-arabinitol ratio in diagnosis of invasive candidiasis in newborn infants. J. Clin. Microbiol. 38, 3039-3042.

[17] Lord, R.S., Burdette, Ch.K., Bralley, J.A. 2004. Urinary markers of yeast overgrowth. Integrative Medicine 3, $24-29$.

[18] Portaluppi, F., Touitou, Y., Smolensky, M.H. 2008. Ethical and methodological standards for laboratory and medical biological rhythm research. Chronobiol. Int. 25, 999-1016.

[19] Grys, W., Kałużna-Czaplińska, J., Rynkowski, J. GC-ECD method for determination of urinary D-/L-ratios in children. 4 th International Interdisciplinary Technical Conference of Young Scientists, Proceedings; 2011 May 18-20; Poznań, Poland.

[20] Lewith, G.T., Chopra, S., Radcliffe, M.J., Abraham, N., Prescott, P., Howarth, P.H. 2007. Elevation of Candida IgG antibodies in patients with medically unexplained symptoms. J. Altern. Complement. Med.13, 1129-1133.

[21] Truss, C.O. 1984. Metabolic abnormalities in patients with chronic candidiasis the acetaldehyde hypothesis. J. Orthomolecular. Psychiatry 13, 66-93.

[22] Asero, R., Bottazzi, G. 2004. Clinical features of patients showing Candida hypersensitivity: an observational study. J. Invest. Allergol. Clin. Immunol. 14, 309-311.

[23] Rabalais, G.P., Samiec, T.D., Bryant, K.K., Lewis, J. 1996. Invasive candidiasis in infants weighing more than 2500 grams at birth admitted to a neonatal intensive care unit. Pediatr. Infect. Dis. J. 15, 348-352.

[24] Hino, M., Tatsumi, N., Yamane, T., Ohta, I.K., Takubo, T., Yabuuchi, M. 2000. New enzymatic method for determining D-arabinitol in serum. J. Basic Microbiol. 40, 363-368.

[25] Katz, E., Willner, I., Wang, J. 2004. Electroanalytical and bioelectroanalytical systems based on metal and semiconductor nanoparticles. Electroanalysis 16, 19-44.

[26] Ahmed, Z. 2001. The properties of Candida formata R28 for D-arabitol production from D-glucose. J. Biol. Sci. 1, 1005-1008.

[27] Vas, G., Conkrite, K., Amidon, W., Qian ,Y., Banki, K., Perl, A. 2006. Study of transaldolase deficiency in urine samples by capillary LC-MS/MS. J. Mass Spectrom. 41, 463-469.

[28] Stradomska, T.J., Mielniczuk, Z. 2002. Gas chromatographic determination of D- / L-arabinitol ratio in healthy Polish children. J Chromatogr B 773, 175-181.

[29] Wang, F., Liao, Y., Ren, Y., Chen, Z. 2010. A novel method for D-arabinitol determination based on a nanostructured sensing film by one-step, Electrodeposition. Microchim. Acta 170, 9-15.

[30] Lehtonen, L., Anttila ,V.-J., Ruutu, T., Salonen, J., Nikoskelainen, J., Eerolaand, E., Ruutu, P.1996. Diagnosis of disseminated candidiasis by measurement of urine d-arabinitol/l-arabinitol ratio. J. Clinic. Microbiol. 34, $2175-2179$.

[31] Stradomska, T.J., Sobielarska, D., Mielniczuk, Z., Jagiełłowicz, D., Syczewska, M., Dzierżanowska, D. 2010. Determination of urinary D-/L-arabinitol ratios as a biomarker for invasive candidiasis in children with cardiac diseases. J. Med. Microbiol. 59,1490-1496.

[32] Christensson, B., Wiebe, T., Pehrson, Ch., Larsson, L. 1997. Diagnosis of invasive candidiasis in neutropenic children with cancer by determination of d-arabinitol/l-arabinitol ratios in urine. J. Clinic. Microbiol. 35, 636-640.

[33] Sigmundsdóttir, G., Christensson, B., Bjorklund, L.J., Håkansson, K., Pehrson, Ch., Larsson, L. 2000. Urine darabinitol/l-arabinitol ratio in diagnosis of invasive candidiasis in newborn infants. J. Clinic. Microbiol. 38, 3039-3042.

[34] Stradomska, T.J., Bobula-Milewska, B., Bauer, A., Mielniczuk, Z., Dabkowska, M., Syczewska, M., Dzierżanowska, D. 2005. Urinary d-Arabinitol/l-Arabinitol levels in infants undergoing long-term antibiotic therapy. J. Clin. Microbiol. 43, $5351-5354$ 